\title{
Calcipotriol and betamethasone dipropionate in the treatment of mild-to-moderate psoriasis: a cost-effectiveness analysis of the ointment versus gel formulation
}

\author{
This article was published in the following Dove Press journal: \\ ClinicoEconomics and Outcomes Research \\ 12 September 2012 \\ Number of times this article has been viewed
}

\section{Giorgio L Colombo ${ }^{1,2}$ Sergio Di Matteo ${ }^{2}$ \\ Giacomo Bruno² \\ Giampiero Girolomoni ${ }^{3}$ \\ Gino Antonio Vena ${ }^{4}$ \\ 'University of Pavia, Department of Drug Sciences, School of Pharmacy, Pavia, Italy; ${ }^{2}$ S.A.V.E. Studi Analisi Valutazioni Economiche, Milan, Italy; ${ }^{3}$ Sections of Dermatology and Venereology, Department of Medicine, University of Verona, Verona, Italy; ${ }^{4}$ Department of Biomedical Sciences and Human Oncology, Unit of Dermatology and Venereology University of Bari, Bari, Italy}

Background: Psoriasis is a chronic inflammatory skin disease with a major impact on the quality of life of affected individuals. Topical therapy has an important role in the treatment of psoriasis. Poor treatment outcomes from topical therapy regimens likely result from poor adherence and ineffective use of medication.

Methods: A cost-minimization analysis was performed with the purpose of assessing the use of a gel containing calcipotriol and betamethasone dipropionate (Dovobet ${ }^{\circledR}$ gel) versus the ointment formulation (Dovobet ointment) in the treatment of psoriasis. The analysis was carried out using a Markov model with a one-year time horizon in a hypothetical cohort of patients with a Psoriasis Area and Severity Index score $<10$. The model simulates different therapy adherence scenarios for the two different formulations.

Results: The Dovobet gel strategy allows a 5\% reduction in the number of patients who could potentially be treated with more expensive therapies (biologics and conventional systemic drugs) in comparison with the Dovobet ointment strategy, with a consequent impact on costs for the National Healthcare Service. The total annual cost of Dovobet gel is about $€ 407.00$ per patient, ie, $19 \%$ less that the total cost of about $€ 500.00$ of the Dovobet ointment strategy. The base case results were then examined by sensitivity analysis and budget impact analysis to correlate the various scenarios of Dovobet gel use with cost savings to the National Healthcare Service.

Conclusion: The Dovobet gel strategy seems more acceptable to patients, shows better overall adherence, and appears to be favorable from the pharmacoeconomic point of view than the ointment formulation for treatment of patients with mild-to-moderate psoriasis.

Keywords: pharmacoeconomics, cost-minimization, cost-consequences, psoriasis, calcipotriol and betamethasone dipropionate, patient adherence

\section{Introduction}

Psoriasis is a chronic inflammatory disease of the skin, affecting about $1 \%-3 \%$ of the world population and almost $2 \%$ of the European population, with about $1,500,000$ $1,800,000$ people affected in Italy. ${ }^{1-3}$ The most common form is plaque-type psoriasis, an immune-mediated condition affecting about $90 \%$ of patients with the disease. Around $20 \%-30 \%$ of cases are moderate-to-severe. With its high incidence, chronic nature, and unsightliness of lesions, psoriasis has a profound impact on quality of life for those affected by the disease. The severity of psoriasis is defined by the extent of body surface area involved, by lesion characteristics, and by the impact of the disease on quality of life. ${ }^{4}$ In general, patients with involvement of over $10 \%$ of body
Correspondence: Giorgio L Colombo S.A.V.E. Studi Analisi Valutazioni Economiche,

Via Previati 74, Milan 20149, Italy

Tel +3902485 I 9230

$\mathrm{Fax}+390273960369$

Email giorgio.colombo@savestudi.it 
surface area, a Psoriasis Area Severity Index $($ PASI) $>10$, or a Dermatology Life Quality Index $>10$ are considered to have moderate-to-severe disease and as such are candidates for systemic therapy. ${ }^{5-7}$ Psoriasis can be associated with other diseases. ${ }^{8}$ The most common comorbidities are psoriatic arthritis, anxiety disorders, and/or depression..$^{9-11}$ More recently, an association has also been reported between psoriasis and metabolic disorders, including abdominal obesity, atherogenic dyslipidemia, arterial hypertension, and diabetes, all of which induce an unfavorable cardiovascular risk profile. ${ }^{12-17}$ The presence of these comorbidities needs to be evaluated carefully in patients with psoriasis in order for the dermatologist to be able to refer the patient to the appropriate specialist and to guide selection of the most effective treatment. Many systemic treatments, such as cyclosporine and methotrexate, can have a negative effect on the cardiovascular risk profile, especially in the long term. ${ }^{13}$ Moreover, patients with cardiovascular disorders are often on polypharmacy, so it is necessary to take all potential drug interactions into consideration before choosing a treatment for psoriasis.

Psoriasis is chronic in nature, and patients with the disease usually need continuous care, with ongoing costs to both patients and to the National Healthcare Service. ${ }^{18}$ From a pharmacoeconomic point of view, many factors need to be considered with regard to their influence on the costs of psoriasis, including increasing costs of prescription and overthe-counter drugs, hospitalizations, treatment or diagnostic procedures, ${ }^{19,20}$ and issues regarding patient adherence and persistence with treatment.

Topical therapy has an important role in the treatment of psoriasis. It is effective and has a favorable safety profile, as shown in the clinical trials. However, poor treatment outcomes from topical therapy regimens can result from poor adherence and ineffective use of medication. ${ }^{21}$ Topical treatment can be troublesome, time-consuming, and difficult for patients. Use of these products might also be affected by cosmetic issues, spreadability, greasiness, and topical medication visible on the skin. Improving adherence with topical treatment is important because it is associated with a better clinical outcome. ${ }^{22,23}$ Patients with psoriasis consistently report that treatment is one of the most negative aspects of the disease. ${ }^{7}$ Lack of adherence results in a poorer prognosis, more hospitalizations, and significantly higher health care costs. ${ }^{24}$ Given that information on the economic impact of noncompliance with topical treatment of psoriasis is very limited, ${ }^{21}$ we carried out a pharmacoeconomic simulation aimed at assessing the costs of two topical formulations, ie, a gel and an ointment, showing different levels of adherence with treatment of mild-to-moderate psoriasis, applying it to the Italian population, and correlating costs with varying degrees of disease severity.

\section{Materials and methods}

An economic analysis was developed to assess the impact on the Italian National Healthcare Service in terms of costs and consequences of the use of two formulations of calcipotriol and betamethasone dipropionate, ie, Dovobet ${ }^{\circledR}$ gel and ointment, in the treatment of mild-to-moderate psoriasis. We carried out a cost-minimization analysis ${ }^{25}$ because the two formulations have comparable efficacy, but the easier application of the gel formulation in comparison with the ointment determines better patient adherence with the gel, with a consequent delay in the use of subsequent more expensive systemic therapies, and a consequent cost saving to the National Healthcare System. ${ }^{26,27}$ We performed the analysis from the point of view of the National Healthcare System as a thirdparty payer. ${ }^{28}$ For this reason, only direct costs (expressed in Euros, $€$ ) determined by the use of the two treatments for the year $2012^{29}$ were included in the analysis.

\section{Structure of the model}

The analysis used a Markov decision model with a one-year time horizon for a hypothetical cohort of patients with mildto-moderate psoriasis (PASI < 10). This time horizon was chosen with the aim of highlighting the potential savings to the National Healthcare System in the short term when using one formulation with respect to the other. Adverse events deriving from the different therapeutic alternatives were not considered, because both formulations have been shown to have an adverse event profile comparable with that of controls. ${ }^{30,31}$ The decision model considered 14 exhaustive and mutually exclusive health states. Thirteen 4-week time intervals were considered. The costs and consequences of use of the two formulations were calculated as a function of the number of psoriasis patients populating each of the 182 cells generated by the possible combinations of health states and time intervals. The proposed model assumes a difference between a treatment with optimal adherence (gel), corresponding to $75 \%$ in a year, with respect to a treatment involving a drug formulation with lower patient adherence (ointment), which decreases with time. Therefore, for the gel treatment arm, the model assumes that $75 \%$ of patients with mild-to-moderate psoriasis using topical drugs as needed remain adherent to therapy; for the ointment treatment arm, optimal adherence (comparable with gel) is assumed only in 
the first cycle ( 4 weeks) of treatment; from week 8 onwards, a linear progression over time was presumed for lower adherence (19\%), with $61 \%$ adherence after 52 weeks. ${ }^{26,27,32}$

\section{Patients and transition probabilities}

Patients not responding to topical therapy followed the treatment protocol described below, as outlined in the literature. ${ }^{33}$ Approximately half of the patients visited their general practitioners, $29 \%$ of nonresponders were retreated using another topical drug, and the rest were referred to a specialist; the majority $(80 \%)$ of patients visiting a specialist $(71 \%$ of nonresponders) were treated with phototherapy, some (19\%) with conventional systemic treatment, and biologic drugs were used in very rare cases $(1 \%) \cdot{ }^{34}$ In the event of relapse on topical drugs and phototherapy, patients were retreated with this strategy; patients not responding to phototherapy were switched to conventional systemic drug therapy and, if this therapy failed, they were prescribed a biologic medication that was continued until the end of the study year, even in the event of failure. The protocol for patients not responding to topical therapy is described in Figure 1, with efficacy data shown in Table 1. The efficacy parameter chosen was PASI 75 , ie, the proportion of patients showing a $\geq 75 \%$ improvement in lesions compared with baseline.

\section{Resource consumption and costs}

The cost items considered in the model and the relative sources for their valuation are listed in Table 2. Unit costs (expressed in Euros for the year 2012) were multiplied by the frequency of treatment over a 4-week period. No discount rate was applied, because the time horizon of the model was one year. We considered the selling price for topical treatments and systemic drugs, including temporary price reductions provided by the Italian Medicines Agency pricing specifications of July 3, 2006 and September 27, 2006. Ex-factory prices were used for biologic drugs, given that they are only dispensed in hospital. ${ }^{35}$ Fees for specialist and general practitioner visits were taken from outpatient rates in force in Italy. ${ }^{36} \mathrm{~A}$ univariate sensitivity analysis was then performed on cost values in order to assess variations in the base case and to identify threshold values for which the base case result showed significant variations. ${ }^{25}$ Finally, a budget

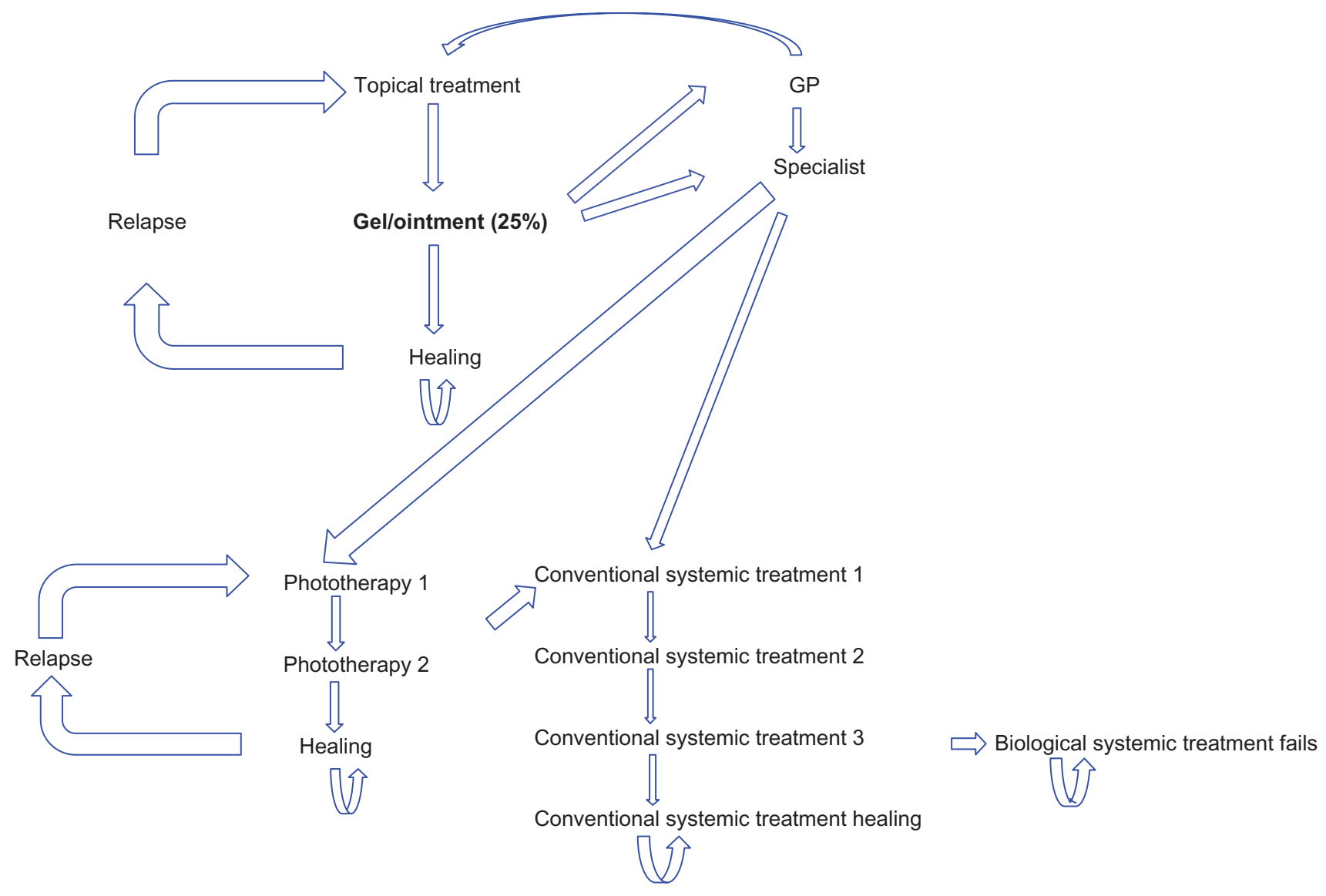

Figure I Structure of the model: pathway of the patient not responding to topical treatment. 
Table I Efficacy data of the model

\begin{tabular}{|c|c|c|}
\hline Therapy & PASI $\geq 75$ & Source \\
\hline \multirow[t]{3}{*}{ Dovobet } & \multirow[t]{3}{*}{$19.7 \%$} & Langley et $\mathrm{a}^{43}$ \\
\hline & & Patients adherent to ointment \\
\hline & & treatment (4 weeks) $98.41 \%$ \\
\hline Phototherapy & $76.6 \%$ & Bottomley et a ${ }^{44}$ \\
\hline Acitretin & $43.0 \%$ & Geiger et al ${ }^{45}$ \\
\hline Methotrexate & $35.5 \%$ & Saurat et $\mathrm{al}^{46}$ \\
\hline Cyclosporine & $33.0 \%$ & \multirow[t]{2}{*}{ Schmitt et $\mathrm{al}^{47}$} \\
\hline Weighted mean efficacy & $36 \%$ & \\
\hline Infliximab & $80.0 \%$ & \multirow[t]{6}{*}{ Reich et al ${ }^{48}$} \\
\hline Adalimumab & $58.0 \%$ & \\
\hline Etanercept $50 \mathrm{mg}$ & $52.0 \%$ & \\
\hline Etanercept $25 \mathrm{mg}$ & $39.0 \%$ & \\
\hline Ustekinumab 45 mg & $39.0 \%$ & \\
\hline Weighted mean efficacy & $54.0 \%$ & \\
\hline Relapse probability & $41.8 \%$ & Naldi et a ${ }^{33}$ \\
\hline \multicolumn{3}{|l|}{ with topical drugs } \\
\hline Relapse probability & $11.6 \%$ & Assumption of the authors \\
\hline with phototherapy & & \\
\hline
\end{tabular}

Abbreviation: PASI, Psoriasis Area Severity Index.

impact analysis was carried out to quantify the potential economic consequences for the Italian National Healthcare System of the use of Dovobet gel for treatment of patients with psoriasis. ${ }^{29,37}$

\section{Results}

This economic model assesses the impact of Dovobet gel versus ointment in two respects, ie, the percentage distribution of patients treated with the different therapeutic options, and the overall average cost per patient (including general practitioners and specialist visits, topical and systemic drugs). Figure 2 shows that, in comparison with the Dovobet ointment strategy, use of Dovobet gel reduces the number of patients potentially needing treatment with more costly therapies by $5 \%$, in spite of an increase in resource consumption for topical therapies. This percentage reduction has a large impact on the overall treatment cost.

The total annual cost for the Dovobet gel strategy was $€ 406.63$ per patient, ie, $18.6 \%$ less that the total cost of $€ 499.90$ for the Dovobet ointment strategy (Figure 3). This result reflects the fact that, as a result of better compliance with Dovobet gel during the simulation year, $81 \%$ of patients treated with topical drugs only accounted for $16 \%$ of total costs. Breaking down the costs related to the two strategies, it can be seen that the decrease in expenditure for Dovobet gel is essentially linked to a decrease in the use of resources for biologic and conventional systemic drugs.

Being more acceptable to patients, the Dovobet gel strategy showed better overall adherence and, at the proposed selling price (€33.17), appears to be a more favorable choice than the ointment formulation from the clinical and economic points of view for the treatment of mildto-moderate psoriasis. The results were then examined by sensitivity analysis and budget impact analysis. The sen-

Table 2 Cost of treatments and relative sources

\begin{tabular}{|c|c|c|c|}
\hline & Unit cost & Total cost for 4 weeks & Source \\
\hline \multicolumn{4}{|l|}{ Topical drugs } \\
\hline Dovobet $^{\circledR}$ gel & $€ 33.17$ & $€ 30.96$ & AIFA transparency lists $201 \mathrm{I}^{35}$ \\
\hline Dovobet ${ }^{\circledR}$ ointment & $€ 27.99$ & $€ 26.12$ & AIFA transparency lists $201 I^{35}$ \\
\hline \multicolumn{4}{|l|}{ Phototherapy } \\
\hline \multirow[t]{2}{*}{ UV-light treatment* } & $€ 5.00$ & $€ 60.00$ & Colombo et al. ${ }^{18}$ Moderate and severe \\
\hline & & & plaque psoriasis: cost-of-illness study in Italy \\
\hline \multicolumn{4}{|l|}{ Conventional systemic drugs } \\
\hline Acitretin & $€ 32.73$ & $€ 45.82$ & AIFA transparency lists $201 I^{35}$ \\
\hline Methotrexate & $€ 38.47$ & $€ 38.47$ & AIFA transparency lists $2011^{35}$ \\
\hline Cyclosporine & $€ 22.59$ & $€ 265.66$ & AIFA transparency lists $201 I^{35}$ \\
\hline Weighted mean & & $€ \mid 49.43$ & \\
\hline \multicolumn{4}{|l|}{ Biotechnological drugs } \\
\hline Infliximab & $€ 542.14$ & $€ 1,275.12$ & AIFA transparency lists 2011 - ex factory prices ${ }^{35}$ \\
\hline Infliximab - administration & $€ 22.51$ & $€ 3.78$ & AIFA transparency lists 2011 - ex factory prices ${ }^{35}$ \\
\hline Adalimumab $40 \mathrm{mg}$ & $€ 1,015.12$ & $€ 1,092.27$ & AIFA transparency lists 2011 - ex factory prices ${ }^{35}$ \\
\hline Etanercept $50 \mathrm{mg}$ & $€ 969.62$ & $€ 969.62$ & AIFA transparency lists 2011 - ex factory prices ${ }^{35}$ \\
\hline Etanercept $25 \mathrm{mg}$ & $€ 484.74$ & $€ 969.48$ & AIFA transparency lists 2011 - ex factory prices ${ }^{35}$ \\
\hline Ustekinumab 45 mg & $€ 2,842.88$ & $€ I, 34 I .84$ & AIFA transparency lists 2011 - ex factory prices ${ }^{35}$ \\
\hline Weighted mean & & $€ 807.24$ & \\
\hline \multicolumn{4}{|l|}{ Visits } \\
\hline General practitioner visit & $€ 22.5 \mathrm{I}$ & $€ 22.51$ & Outpatient visit hospital rates ${ }^{36}$ \\
\hline Dermatologist & $€ 22.51$ & $€ 22.51$ & Outpatient visit hospital rates ${ }^{36}$ \\
\hline
\end{tabular}

Note: *Treatment per session.

Abbreviations: AIFA, Italian Medicines Agency. 


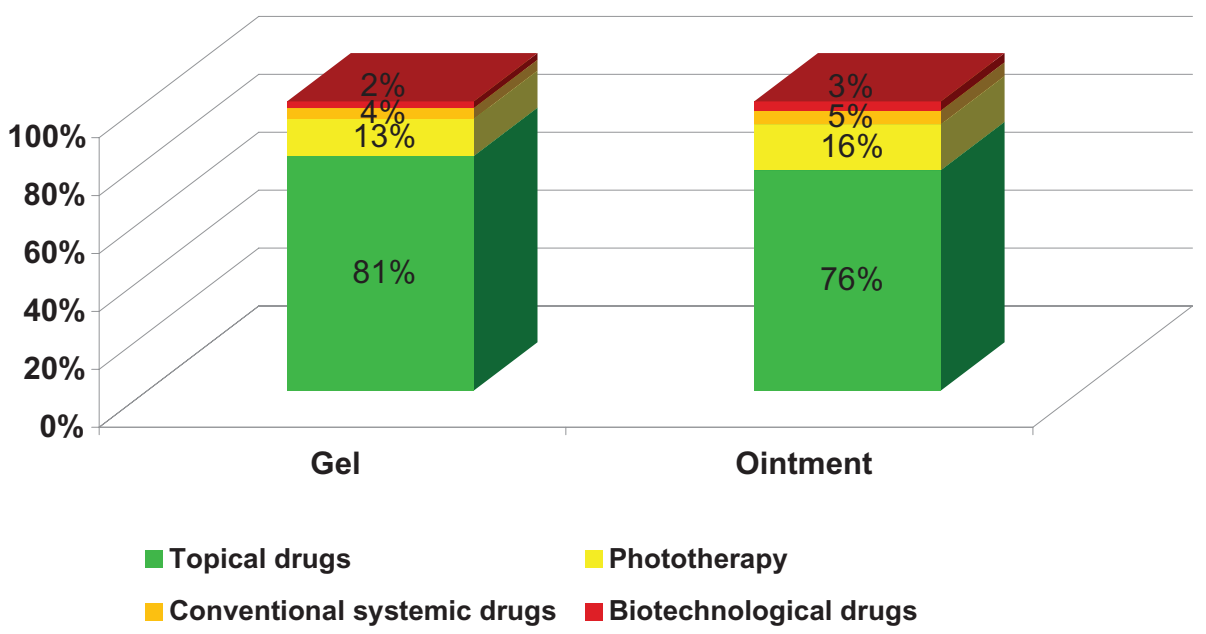

Figure 2 Percentage distribution of patients by treatment.

sitivity assessment was carried out with variations in the cost of Dovobet gel. In the base case, the cost of Dovobet gel was $€ 0.67$ per g (ex-factory price before the two price reductions provided for by the Italian Medicines Agency pricing specifications of July 3, 2006 and September 27, 2006). With variations ranging from $€ 0.65$ to $€ 0.69$, the total annual cost for the Dovobet gel arm becomes $€ 404.66$ and $€ 408.53$, respectively.

The budget impact evaluation (Table 3) considered the number of patients treated with the ointment in 2011, ie, 228,836 patients according to Information Management System data. ${ }^{36}$ Four scenarios were then examined, assuming variations in the number of patients who used Dovobet gel: scenario $1,100 \%$ of patients treated with ointment and $0 \%$ treated with gel (current situation, reference scenario); scenario $2,40 \%$ of patients treated with gel and $60 \%$ with ointment; scenario $3,50 \%$ of patients treated with gel and $50 \%$ with ointment (proposed scenario); scenario 4, 60\% of patients treated with gel and $40 \%$ with ointment. In scenarios 2 and 4, it was decided to consider the impact of a $10 \%$ increase or decrease in the consumption of Dovobet gel. Table 3 shows the number of patients calculated for the different scenarios as a function of percentage use of Dovobet gel.

The number of patients in the various scenarios was multiplied by the overall mean annual cost per patient treated with Dovobet gel (€406.63) or with Dovobet ointment (€499.90), as generated by the cost minimization analysis. The results of the various analyses are summarized below and shown in Table 4.

In scenario 1 (100\% of patients treated with ointment), the overall cost of therapy (including phototherapy, conven-

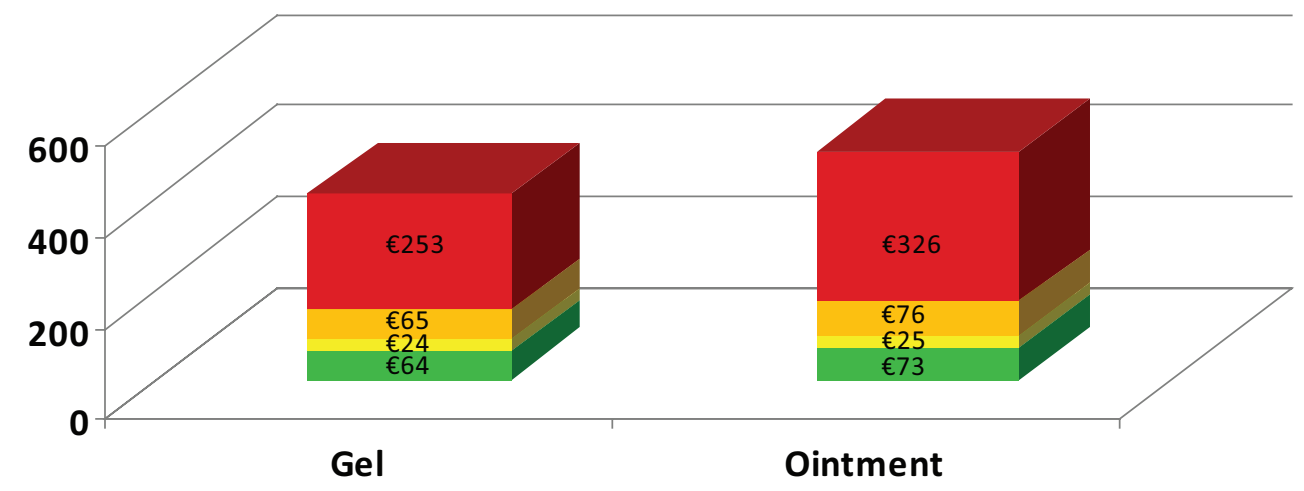

Topical drugs

Conventional systemic drugs
Phototherapy

Biotechnological drugs

Figure 3 Total annual average costs $(€)$ per patient by treatment. 
Table 3 Variation of the percentage of patients treated with Dovobet gel and ointment

\begin{tabular}{|c|c|c|c|c|}
\hline & $\begin{array}{l}\text { Scenario \# I } \\
100 \% \text { ointment (reference scenario) }\end{array}$ & $\begin{array}{l}\text { Scenario \# } 2 \\
40 \% \text { gel }\end{array}$ & $\begin{array}{l}\text { Scenario \# } 3 \\
50 \% \text { gel (proposed scenario) }\end{array}$ & $\begin{array}{l}\text { Scenario \# } 4 \\
60 \% \text { gel }\end{array}$ \\
\hline Ointment & 228,836 & 137,302 & $|14,4| 8$ & 91,534 \\
\hline Gel & & 91,534 & || $4,4 \mid 8$ & 137,302 \\
\hline Total & 228,836 & 228,836 & 228,836 & 228,836 \\
\hline
\end{tabular}

tional systemic drugs, and biologics) for 228,836 patients was $€ 114.40$ million. This is the current and therefore reference scenario. Scenario 3, corresponding to the use of Dovobet gel by $50 \%$ of all patients, generates an overall cost saving of $€ 10.7$ million, with savings on all therapies in the gel treatment arm, for a total estimated expenditure of $€ 103.7$ million. As for scenarios 2 and 4 , the $\pm 10 \%$ variation in the use of Dovobet gel compared with scenario 3 produces a $€ 2.1$ million increase in the amount saved. Therefore, we can assume that a $10 \%$ increase in patients treated with Dovobet gel instead of ointment would produce a saving of about $€ 2.1$ million on overall expenditure for therapy. Indeed, if $60 \%$ of patients used the gel formulation, the overall expenditure would be simultaneously reduced by $€ 12.8$ million ( $-11.1 \%$ ), dropping from $€ 114.4$ to 101.6 million (Table 4$)$.

\section{Discussion}

Dovobet gel contains a combination of calcipotriol $50 \mu \mathrm{g} / \mathrm{g}$ and betamethasone dipropionate $0.5 \mathrm{mg} / \mathrm{g}$, is specifically intended to treat plaque psoriasis, and is not reimbursed by the Italian National Healthcare Service as yet. In various studies involving a large number of patients with mild-to-moderate psoriasis, Dovobet gel was shown to be more effective than the single active ingredients used as monotherapy, one reason for this being the lower rate of side effects requiring cessation of treatment. The combination of the two active ingredients in a gel formulation may result in higher adherence to therapy in comparison with the ointment formulation currently available and reimbursed by the Italian National Healthcare Service, thereby increasing patient compliance with topical treatment. The Dovobet gel formulation contributes positively to better overall compliance and aids management of the disease, so this therapeutic option goes alongside the ointment formulation in the management of psoriasis patients on topical treatment, reducing the number of patients who need to receive subsequent systemic therapy.

However, based on our analysis, it is necessary to point out again that Dovobet gel is not reimbursed by the Italian National Healthcare Service as yet. The price adopted in our economic assessment, ie, $€ 0.67$ per g (ex-factory price before the two price reductions provided for by the Italian Medicines Agency pricing specifications of July 3, 2006 and September 27, 2006), was calculated as the average European price for a $30 \mathrm{~g}$ pack based on prices in France, the UK, Spain, and Greece, and was 5\% lower than the average European price, which includes countries where the price per $\mathrm{g}$ applies to $60 \mathrm{~g}$ and $120 \mathrm{~g}$ packs. Based on the proposed Markov decision model, the cost value per $g$ of Dovobet gel generating a total annual cost of $€ 499.90$ (Dovobet ointment) is $€ 1.65$. $^{38}$

In the proposed model, the Dovobet gel formulation has a double benefit, ie, a benefit for the patient by increasing adherence and so effectiveness of treatment, and a benefit for the Italian National Healthcare Service because better compliance reduces expenditure on mild-to-moderate psoriasis by $19 \%$, delaying the use of particularly expensive systemic therapies, including biologics. Moreover, the sensitivity analysis showed that, when the use of Dovobet gel increases, the Italian National Healthcare Service saving on total treatment costs for psoriasis (calculated as the number of patients currently treated with Dovobet ointment) increases by $€ 2.1$ million for every 10 percent points of increase in the use of Dovobet gel.

The study has a few limitations, the most important of which concerns the quality of the data entered into the model. The efficacy parameters, for example, are based on studies with a limited time frame and may therefore be inadequate

Table 4 Comparison of overall expenditure for psoriasis treatment with varying use of Dovobet gel and ointment

\begin{tabular}{lllll}
\hline$€$ & Scenario \# I & Scenario \# 2 & Scenario \# 3 & Scenario \# 4 \\
\hline Overall expenditure & $|\mathrm{I} 4,4| 7,074$ & $105,882,662$ & $103,749,060$ & $101,615,457$ \\
Delta vs scenario \# I & & $-8,534,4 \mid I$ & $-10,668,014$ & $-12,801,617$ \\
Delta vs scenario \# 3 & & $2,133,603$ & & $-2,133,603$ \\
\hline
\end{tabular}


for modeling treatment of a chronic disease for a longer period. Another important limitation is the assumptions on which the analysis is based, which are necessary to simplify the model or need to be used in cases of incomplete data. Specifically, this limitation concerned transition probabilities, which were missing in some cases and thus were assumed to remain constant over time, and involved data derived from different literature sources but considered to be representative of an Italian population. Moreover, the present study does not address patient quality of life, although inclusion of this would probably have improved the economic impact of the Dovobet gel formulation. ${ }^{18,39} \mathrm{~A}$ further limitation could be consistency in duration of reported adherence with the gel formulation. Indeed, some international research has reported a decrease in patient adherence with any topical therapy over time. ${ }^{40}$ However, in our study, we tried to compare the differences between gel and ointment only from a marginal point of view. Inclusion of further factors relating to decreased adherence would have penalized both formulations, with consequent underestimation of the adherence effect from a pharmacoeconomic standpoint, and reduced clarity concerning the potential role of the gel formulation in improving patient compliance with therapy in clinical practice. In spite of these limitations, measurement and understanding of the concept of adherence in the treatment of psoriasis are not only critical factors for determining the effectiveness and safety of a given drug, but they are also important for creation of programs aimed at improving the quality of use of these drugs. ${ }^{41,42}$ Poor adherence inevitably leads to a poor treatment outcome. Little is known about interventions to increase adherence, and few prospective trials have been carried out, but it is clear that adherence to topical treatment improves around the time of return visits. Prospective studies are needed to demonstrate the impact of interventions designed to enhance adherence and the effect of improved adherence on treatment outcomes. ${ }^{21}$ Adherence to medication is influenced by multiple factors. Patient characteristics, disease characteristics, and treatment characteristics all affect medication adherence and treatment outcome. In turn, treatment outcome influences satisfaction with treatment, which in turn influences medication adherence. Interaction with the physician also affects medication adherence and indirectly influences treatment outcome. ${ }^{21}$

For these reasons, it is important to evaluate the economic consequences of lack of adherence for patients and for the Italian National Healthcare Service. Various studies like this one have demonstrated ${ }^{41}$ that inadequate adherence with therapy (how far the patient follows the prescribed regimen of doses and administration intervals) and persistence with treatment (duration of time between the start and cessation of therapy) result in increased morbidity and mortality for a wide range of diseases and, at the same time, lead to significantly increased costs related to health management.

\section{Disclosure}

The study was financially supported by LEO Pharma Spa, Rome, Italy.

\section{References}

1. Plunkett A, Marks R. A review of the epidemiology of psoriasis vulgaris in the community. Australas J Dermatol. 1995;39:225-232.

2. Sterry W, Barker J, Boehncke WH, et al. Biological therapies in the systemic management of psoriasis: International Consensus Conference. Br J Dermatol. 2004;151 Suppl 69:3-17.

3. Naldi L, Colombo P, Benedetti Placchesi E, et al. Study design and preliminary results from the pilot phase of the Praktis study: self reported diagnoses of selected skin diseases in a representative sample of the Italian population. Dermatology. 2004;208:38-42.

4. Finlay AY. Current severe psoriasis and the Rule of Tens. Br J Dermatol. 2005;152:861-867.

5. Kirby B, Fortune DG, Bhushan M, et al. The Salford Psoriasis Index: an holistic measure of psoriasis severity. Br J Dermatol. 2000;142: 728-732.

6. Shikiar R, Bresnahan BW, Stone SP, et al. Validity and reliability of patient reported outcomes used in psoriasis: results from two randomized clinical trials. Health Qual Life Outcomes. 2003;1:53.

7. Rapp SR, Exum ML, Reboussin DM, Feldman SR, Fleischer AB Jr, Clark AR. The physical, psychological and social impact of psoriasis. J Health Psychol. 1997;2:525-537.

8. Del Giglio M, Gisondi P, Girolomoni G. The need for long-term continuous therapy in moderate to severe chronic plaque psoriasis. G Ital Dermatol Venereol. 2007;142:269-276.

9. Gisondi P, Girolomoni G, Sampogna F, et al. Prevalence of psoriatic arthritis and joint complaints in large population of Italian patients hospitalized for psoriasis. Eur J Dermatol. 2005;15:279-283.

10. Kimball AB, Jacobson C, Weiss S, et al. The psychosocial burden of psoriasis. Am J Clin Dermatol. 2005;6:383-392.

11. Parisier DM, Bagel J, Gelfand JM, et al. National Psoriasis Foundation clinical consensus on disease severity. Arch Dermatol. 2007;143: 239-242.

12. Neimann AL, Shin DB, Wang X, et al. Prevalence of cardiovascular risks factors in patients with psoriasis. J Am Acad Dermatol. 2006;55: 829-835.

13. Gisondi P, Girolomoni G. Aggiornamento sui trattamenti biologici della psoriasi. [Update on the biological treatment of psoriasis]. G Ital Dermatol Venereol. 2007;142 Suppl 1:1-11. Italian.

14. Gelfand JM, Neimann AL, Shin DB, et al. Risk of myocardial infarction in patients with psoriasis. JAMA. 2006;296:1735-1741.

15. Malerba M, Gisondi P, Radaeli A, et al. Psoriasis and risk of myocardial infarction. JAMA. 2007;297:361-362.

16. Shapiro J, Cohen AD, David M, et al. The association between psoriasis, diabetes mellitus, and atherosclerosis in Israel: a case-control study. J Am Acad Dermatol. 2007;56:629-634.

17. Boehncke $\mathrm{S}$, Thaci $\mathrm{D}$, Beschmann H, et al. Psoriasis patients show signs of insulin resistance. Br J Dermatol. 2007;157:1249-1251.

18. Colombo GL, Altomare GF, Peris K, et al. Moderate and severe plaque psoriasis: cost-of-illness study in Italy. Ther Clin Risk Manag. 2008;4: 559-568.

19. Braathen LR. Cost of caring for hospital-based patients in dermatology in Europe. J Eur Acad Dermatol Venereol. 2001;15:292. 
20. Dehkharghani S, Bible J, Chen JG, et al. The economic burden of skin disease in the United States. J Am Acad Dermatol. 2003;48: 592-599.

21. Feldman SR, Horn EJ; International Psoriasis Council. Psoriasis: improving adherence to topical therapy. J Am Acad Dermatol. 2008;59: 1009-1016.

22. Ulff E, Maroti M, Kettis-Lindblad A, et al. Single application of a fluorescent test cream by healthy volunteers: assessment of treated and neglected body sites. Br J Dermatol. 2007;156:974-978.

23. Carroll CL, Feldman SR, Camacho FT, Balkrishnan R. Better medication adherence results in greater improvement in severity of psoriasis. Br J Dermatol. 2004;151:895-697.

24. McDonald HP, Garg AX, Haynes RB. Interventions to enhance patient adherence to medication prescriptions: scientific review. JAMA. 2002;288:2868-2879.

25. Drummond MF, O'Brien BJ, Stoddart GL, et al. Methods for the Economic Evaluation of Health Care Programmes. 3rd ed. New York, NY: Oxford University Press; 2006.

26. Reich K, Bewley A. What is new in topical therapy for psoriasis? J Eur Acad Dermatol Venereol. 2011;25 Suppl 4:15-20.

27. Queille-Roussel C, Hoffmann V, Enevold A, Ganslandt C. Use of a psoriasis plaque test in the development of a gel formulation of calcipotriol and betamethasone dipropionate for scalp psoriasis. J Dermatolog Treat. 2011.[Epub ahead of print].

28. Jonsson B. Changing health environment: the challenge to demonstrate cost-effectiveness of new compounds. Pharmacoeconomics. 2004;22 Suppl 4:5-10.

29. Italian Health Economics Association. Proposta di linee guida per la valutazione economica degli interventi sanitari in Italia. Italian guidelines proposal on how to conduct economic evaluation studies of health programs. Pharmacoeconomics Italian Research Articles. 2009;11:83-93. Italian.

30. Fleming C, Ganslandt C, Guenther L, et al. Calcipotriol plus betamethasone dipropionate gel compared with its active components in the same vehicle and the vehicle alone in the treatment of psoriasis vulgaris: a randomised, parallel group, double-blind, exploratory study. Eur J Dermatol. 2010;20:465-471.

31. Kaufmann R, Bibby AJ, Bissonnette R, et al. A new calcipotriol/ betamethasone dipropionate formulation (Daivobet ${ }^{\mathrm{TM}}$ ) is an effective oncedaily treatment for psoriasis vulgaris. Dermatology. 2002;205:389-393.

32. Hol K. Patient preference for topical psoriasis formulations. Available from: http://www.leo-pharma.se/Files/Billeder/Docs/Hol-EADV.pdf. Accessed July 19, 2012.

33. Naldi L, Chatenaud L, Castelli E, et al. Trattamento della psoriasi con farmaci sistemici in Italia, Psocare, Primo Rapporto 2006. [Treatment of psoriasis with systemic drugs in Italy, Psocare, First Report 2006]. Italian. Available from: http://www.agenziafarmaco.gov.it/it/content/ rapporto-psocare. Accessed July 17, 2012.
34. Berg M, Lirvall M, Nohlgård D, Svensson M, Wictorin Å. Swedish clinical experts interviews August 29th and advisory board meeting October 26, 2011. Data on file. Rome, Italy: LEO Pharma; 2012.

35. Italian Medicines Agency. [List of marketed medicines.] Available from: http://farmaco.agenziafarmaco.it/index.php.Italian. Accessed November 1, 2011.

36. Italian Health Ministry. [2010 National Tariff Nomenclator.] Rome, Italy: Italian Health Ministry; 2011. Italian.

37. Simoens S. Health economic assessment: a methodological primer. Int J Environ Res Public Health. 2009;6:2950-2566.

38. Data on file. Rome, Italy: LEO Pharma; 2012.

39. Colombo GL, Di Matteo S, Peris K, et al. A cost-utility analysis of etanercept for the treatment of moderate-to-severe psoriasis in Italy. Clinicoecon Outcomes Res. 2009;1:53-59.

40. Storm A, Benfeldt E, Andersen SE, Serup J. A prospective study of patient adherence to topical treatments: $95 \%$ of patients underdose. J Am Acad Dermatol. 2008;59:975-980.

41. Borghi C, Cicero AFG. Adherence and persistence with therapy. Giornale Italiano di Farmacoeconomia E Farmaco Utilizzazione. 2008; 1:5-13. Italian.

42. Casula M, Tragni E, Catapano AL. I database amministrativi come fonti di dati per la ricerca farmaco epidemiologica. [The administrative databases as data sources for epidemiological research drug]. CARE I. 2011:33-36. Italian.

43. Langley RG, Gupta A, Papp K, Wexler D, Østerdal ML, Curčić D. Calcipotriol plus betamethasone dipropionate gel compared with tacalcitol ointment and the gel vehicle alone in patients with psoriasis vulgaris: a randomized, controlled clinical trial. Dermatology. 2011;222(2):148-156.

44. Bottomley JM, Auland ME, Morais J, Boyd G, Douglas WS. Costeffectiveness of the two-compound formulation calcipotriol and betamethasone dipropionate compared with commonly used topical treatments in the management of moderately severe plaque psoriasis in Scotland. Curr Med Res Opin. 2007;23(8):1887-1901.

45. Geiger JM. Efficacy of acitretin in severe psoriasis. Skin Therapy Lett. 2003;8(4):1-8.

46. Saurat JH, Stingl G, Dubertret L, et al. CHAMPION Study Investigators. Efficacy and safety results from the randomized controlled comparative study of adalimumab vs. methotrexate vs. placebo in patients with psoriasis (CHAMPION). Br J Dermatol. 2008;158(3):558-566.

47. Schmitt J, Zhang Z, Wozel G, Meurer M, Kirch W. Efficacy and tolerability of biologic and nonbiologic systemic treatments for moderateto-severe psoriasis: meta-analysis of randomized controlled trials. $\mathrm{Br}$ J Dermatol. 2008;159(3):513-526.

48. Reich K, Burden AD, Eaton JN, Hawkins NS. Efficacy of biologics in the treatment of moderate to severe psoriasis: a network meta-analysis of randomized controlled trials. Br J Dermatol. 2012;166(1):179-188.
ClinicoEconomics and Outcomes Research

\section{Publish your work in this journal}

ClinicoEconomics \& Outcomes Research is an international, peerreviewed open-access journal focusing on Health Technology Assessment, Pharmacoeconomics and Outcomes Research in the areas of diagnosis, medical devices, and clinical, surgical and pharmacological intervention. The economic impact of health policy and health systems

\section{Dovepress}

organization also constitute important areas of coverage. The manuscript management system is completely online and includes a very quick and fair peer-review system, which is all easy to use. Visit http://www.dovepress.com/testimonials.php to read real quotes from published authors. 